\title{
Corrupção e ineficiência no Brasil: Uma análise de equilíbrio geral
}

\author{
Francisco de Assis Oliveira Campos \\ Professor - Universidade Federal do Ceará (UFC/DTE) \\ Endereço: Av. da Universidade, 2700 - $2^{\circ}$ andar - Benfica - Fortaleza/CE \\ CEP: 60020-181 - E-mail: camposfao@gmail.com \\ Ricardo A. de Castro Pereira \\ Professor - Universidade Federal do Ceará (UFC/CAEN) \\ Endereço: Av. da Universidade, 2700 - $2^{\circ}$ andar - Benfica - Fortaleza/CE \\ CEP: 60020-181 - E-mail: rpereira@caen.ufc.br
}

Recebido em 18/02/2014. Aceito em 07/07/2015.

\section{Resumo}

O trabalho analisa corrupção e ineficiência no setor público a partir de um modelo de equilíbrio geral calibrado para o Brasil, com foco em agregados macroeconômicos e o bem-estar da economia. Os resultados de exercícios contrafactuais mostram que a eliminação da corrupção e ineficiências nos gastos públicos implicam significativo ganho de bem-estar. Entretanto, eliminando-se somente corrupção o efeito de bem-estar é adverso e expressivo, indicando que a corrupção estaria corrigindo alguma distorção presente na economia. Na hipótese de um possível tradeoff entre políticas de redução de ineficiências e corrupção, reduções nas ineficiências do setor público acompanhadas de aumento de corrupção podem implicar efeitos negativos sobre o produto e o investimento no curto e longo prazos, em que pese o bem-estar aumentar. Ademais, usando como ilustração a flexibilização de normas licitatórias para as obras da copa do mundo e das olimpíadas permitida pela Lei no 12.462 , as simulações sugerem que se a flexibilização vier acompanhada de aumentos na corrupção, poderia haver ganho de bem-estar para o agregado da economia, mas retrairia as trajetórias de crescimento do produto e investimento no curto e longo prazo, mostrando que poderia haver certo dilema na tomada de decisão para fins de implantação de uma política desta natureza.

\section{Palavras-Chave}

Corrupção. Ineficiência. Equilíbrio geral. Bem-estar. Crescimento.

\begin{abstract}
The essay analyzes corruption and inefficiency in the public sector from a general equilibrium model calibrated to Brazil, focusing on macroeconomic aggregates and welfare for the aggregate economy. The results of the counterfactual exercises performed show that the elimination of corruption and inefficiencies in public spending could determinate significant gain in welfare. However, if only corruption is eliminated the welfare

\footnotetext{
- Os autores agradecem as sugestões e críticas dos pareceristas anônimos. Ricardo A. de Castro Pereira, adicionalmente, agradece o financiamento do Programa de Educação Tutorial (PET) da Secretaria de Educação Superior (Sesu) do Ministério da Educação (MEC) e o financiamento dos Institutos Nacionais de Ciência e Tecnologia (INCT) do Conselho Nacional de Desenvolvimento Científico e Tecnológico (CNPq).
} 
effect is negative, indicating that corruption could be eliminating some distortions in this economy. Admitting a tradeoff between corruption and inefficiency, less inefficiency and more corruption could imply reductions in product and investment in the short and long terms and welfare improvement. Using the flexibilization of rules of tender to illustrate the works of the World Cup and the Olympics allowed by the Law No. 12.462, the results of simulations suggest that, if flexible rules reduce inefficiency and increase corruption, it is possible to verify welfare gains and growth reductions, showing a dilemma in taking decisions for the purpose of implementing such policy of this nature.

\section{Keywords}

Corruption. Inefficiency. General equilibrium. Welfare. Growth.

\section{JEL Classification}

H11. H50. E17. O43.

\section{Introdução}

Desde a década de noventa que a corrupção tem se apresentado como uma importante linha de pesquisa econômica, tendo como marco o trabalho empírico de Mauro (1995), que utilizou modelos econométricos cross country para avaliar os efeitos da corrupção sobre os investimentos e o crescimento do produto. Aliás, os modelos usando dados de painel e do tipo cross country dominam as pesquisas empíricas dos efeitos da corrupção sobre o produto e outras variáveis econômicas, ${ }^{1}$ tais como, Tanzi e Davoodi (1997), Treisman (2000), Mauro (2002), Lambsdorff (2003), Svensson (2005), Kaufmann et al. (2002). Entretanto, Cheung (1996) chamou a atenção para a necessidade de se avaliar a corrupção a partir de modelos de equilíbrio geral. Chakrabarti (2001), Acemoglu e Verdier (2000) também desenvolveram modelos de equilíbrio geral para verificar as distorções provocadas pela corrupção sobre algumas variáveis econômicas, no caso salários e alocação de mão de obra. Blackburn et al. (2005), Dzhumashev (2009), Pelegrini e Gerlagh (2004), Neeman et al. (2003), Martinez-Vasquez et al. (2005) utilizaram variantes de modelos de equilíbrio geral para analisar causas e efeitos da corrupção sobre os agregados macroeconômicos (investimento e produto).

1 Apesar de algumas variações, a maioria dos estudos empíricos estimam um modelo de crescimento que é compatível com as regressões de crescimento discutidas e testadas nos trabalhos empíricos de crescimento de Barro (1991), Mankiw et al. (1992) e Renelt e Levine (1992) (ver Ugur e Dasgupta(2011)). 
A corrupção, vista como o abuso do poder público praticado pelo agente para benefício privado (ver World Bank, 1997), está relacionada aos incentivos e aos problemas de agente-principal, especialmente onde há problemas de assimetria de informação, que repercutem negativamente na eficiência burocrática e institucional e na geração de incentivos para o comportamento corrupto (ver Becker, 1968; Klitigaard, 1994). Dada a preferência ao risco do agente, a fragilidade institucional, inclusive a estrutura legal, gera oportunidades para adoção de atitudes que rendam benefícios diante de práticas ilícitas.

A priori, pode-se afirmar que a corrupção prejudicaria a sociedade em vista dos seus efeitos sobre a redução dos investimentos, do nível do produto, da produtividade e da eficiência econômica. A lógica econômica do efeito da corrupção sobre o investimento, canal de transmissão, dar-se-ia em virtude da repercussão sobre a taxa de retorno, visto que a corrupção atuaria como uma despesa que encareceria as inversóes e com isso o custo de oportunidade exigido seria maior, retardando ou evitando a realização do investimento pela iniciativa privada.

A corrupção também reduz os insumos públicos (infraestrutura e serviços públicos), levando a reduções na produtividade do capital privado, por exemplo, no caso de a corrupção ser decorrente da redução da qualidade e quantidade dos materiais e equipamentos das obras de infraestrutura, a vida útil dessas obras deve ser reduzida e a possibilidade de defeitos e disfunções pode repercutir diretamente sobre a produtividade dos agentes econômicos demandadores destes instrumentos públicos.

Em princípio, espera-se que esses efeitos negativos sobre o investimento sejam transmitidos para a dinâmica do crescimento econômico via acumulação de capital ou via produtividade dos fatores de produção (ver Silva et al., 2001). Contudo, de acordo com as principais pesquisas dos efeitos adversos da corrupção sobre os agregados macroeconômicos e a taxa de crescimento do produto, percebe-se que não há consenso quanto ao efeito direto da corrupção sobre o crescimento econômico, havendo, entretanto, concordância sobre as causas adversas da corrupção sobre o investimento privado, que, por conseguinte, reflete-se no crescimento econômico, em que pesem as divergências quanto às magnitudes dos efeitos. 
Ugur e Dasgupta (2011), conduzindo uma meta-análise de achados de 72 pesquisas empíricas, entre elas Mauro (1995), Treisman (2000), Blackburn et al. (2005), Pellegrini e Gerlach (2004), Tanzi e Davoodi (1997), Dzhumashev (2009) e outras bem referenciadas na literatura sobre o assunto, encontram que corrupção tem um efeito negativo sobre o crescimento per capita do produto. Especificamente, Mauro (1995) encontra que corrupção afeta investimento e, por conseguinte, repercute sobre o crescimento econômico; além disso, as magnitudes desses efeitos são estatisticamente expressivas. Dzhumashev (2009) e Blackburn et al. (2005) encontram efeitos diretos significantes da corrupção sobre o crescimento econômico. Por outro lado, Pelegrini e Gerlagh (2004) e MartinezVasquez et al. (2005) não encontram efeitos diretos significantes, embora Pelegrini e Gerlagh (2004) e Martinez-Vasquez et al. (2005) encontrem que os efeitos indiretos são significantes. ${ }^{2}$

A ausência de consenso sobre os efeitos diretos da corrupção sobre o crescimento econômico pode ser explicada pela possibilidade da renda desviada pelo agente privado ser direcionada para outro investimento de maior retorno para a economia ou simplesmente pelo fato dessa renda desviada retornar ao fluxo circular da economia para fins de consumo, compensando os seus efeitos maléficos sobre a demanda agregada. Segundo Beattie (2010), com base na corrupção do Governo de Suharto na Indonésia, se não houver fuga de capital, a corrupção retorna à economia e os prejuízos quanto ao crescimento econômico são reduzidos. Neeman et al. (2003), em um modelo de equilíbrio geral, mostra que o efeito adverso da corrupção sobre o produto é atenuado numa economia fechada, tendo em vista que os recursos da corrupção permanecem na economia. Na mesma perspectiva, Wedeman (1997) argumenta que se a corrupção for do tipo centralizada e a renda proveniente da corrupção for internalizada, a corrupção pode dar segurança as transações, reduzir as regulações excessivas, sendo essa sistemática a provável explicação para o fato de países conhecidamente corruptos, China, Coreia do Sul, Indonésia, Filipinas, entre outras, apresentarem elevadas taxas de crescimento econômico a partir da década de noventa.

2 Os efeitos da corrupção são diretos quando ocorrem via mudança no fator de produtividade total (ou via tecnologia) e indiretos quando são por meio de impacto na atividade econômica e redução na demanda por investimento (Dzhumashev, 2009). 
Portanto, é possível supor que o efeito da corrupção sobre os níveis do produto e sobre o investimento está relacionado ao destino dado à parcela de corrupção, sendo que a sua internalização ao processo produtivo poderia, a priori, determinar que a corrupção não tem graves efeitos sobre os agregados macroeconômicos, podendo, ainda, representar efeitos positivos quando a eficiência do investimento público for menor que a eficiência da parcela de corrupção internalizada nos processos produtivos. Mas também, obviamente, é plausível admitir que caso não houvesse corrupção, os países considerados corruptos, que apresentam elevadas taxas de crescimento, cresceriam ainda mais, conforme salienta Svensson (2005).

Especificamente para o Brasil, Silva et al. (2001) medem os efeitos da corrupção sobre as variáveis econômicas no ano de 1998, encontrando que a corrupção seria responsável por uma perda de renda per capita de US\$2,840.81, valor correspondente a algo em torno de 55\% do PIB per capita deste ano. Carraro et al. (2006), usando um modelo de equilíbrio geral computável, encontra que, para o ano de 1998, o nível de corrupção (volume de recursos envolvidos com corrupção) equivale a $11,36 \%$ do Produto Interno Bruto, o que de acordo com seu modelo implicaria um crescimento do PIB 1,1\% menor que quando comparado com o resultado obtido sem corrupção. Estudo da FIESP (2011), através de metodologia semelhante a Silva et al. (2001), estima, como percentual do PIB, um custo máximo da corrupção no Brasil de 2,3\%.

O principal objetivo deste trabalho é analisar a corrupção no setor público a partir de um modelo de equilíbrio geral calibrado para o Brasil, tendo como foco os agregados macroeconômicos, em especial produto e investimento, e o bem-estar para o agregado da economia, o que se considera uma contribuição relevante tendo em vista a atenção que se tem devotado à corrupção pelas nações e pelos organismos internacionais, principalmente, após a segunda metade da década de 1990, devido aos seus custos econômicos, (ver Elliot, 2002), e o fato do estudo inserir uma medida de bem-estar, o que não se verifica na literatura macroeconômica dos efeitos da corrupção. ${ }^{3}$

Outra investigação que se considera relevante é o exame da possibilidade de existência de tradeoff entre corrupção e ineficiência

3 Trata-se o bem-estar agregado da economia como uma medida de eficiência, não se verificando, apesar de sua importância, questões econômicas distributivas, sociais, morais e culturais que são afetadas pela corrupção. 
no setor público, no sentido de que uma redução da ineficiência, por exemplo, uma redução das regras e aumento do poder discricionário dos agentes públicos, pode implicar aumentos nos níveis de corrupção (ver Klitigaard, 1994; Rose-Ackerman, 2002). Assim, em termos inversos, uma política de combate à corrupção poderia não estar isenta de custos, podendo acarretar aumentos da ineficiência no setor público. Para ilustrar este possível tradeoff, um conjunto de simulações é realizado, tendo como motivação a recente Lei Federal $n^{0} 12.462 / 2011$, que trata do Regime Diferenciado de Contratação Pública - RDC - para as obras e os serviços de engenharia relativas à Copa do Mundo de Futebol de 2014 e aos Jogos Olímpicos de 2016, recentemente estendida para as obras do PAC. ${ }^{4}$ que criou, temporariamente, procedimentos licitatórios mais flexíveis e aumentou o poder discricionário dos agentes públicos, quando confrontados com a Lei de Licitação no 8.666/1993, a qual, segundo o Ministério Público Federal, que entrou com uma Ação Direta de Inconstitucionalidade junto ao Supremo Tribunal Federal, devido à flexibilização das regras, poderia aumentar desvios de recursos públicos.

Vale salientar que o modelo proposto de equilíbrio geral segue a linha de Carraro et al. (2006), Blackburn et al. (2005), Dzhumashev (2009), Pelegrini e Gerlagh (2004), Martinez-Vasquez et al. (2005), mas, diferentemente destes, são analisados impactos de bem-estar, os possíveis efeitos de tradeoff entre corrupção e ineficiência, além da cuidadosa calibração do modelo, especificamente, para o Brasil, a partir de dados recentes.

Além desta introdução, o trabalho consiste, ainda, das seções 2, que especifica o modelo de equilíbrio geral; 3 , que trata da calibração; 4 , que mostra e analisa os resultados dos exercícios contrafactuais propostos; e, por fim, 5, onde destacam-se as principais conclusões.

4 A Lei n ${ }^{\circ} 12.688$, de 18 de julho de 2012 estendeu o RDC para as obras do Programa de Aceleração do Crescimento - PAC. 


\section{O Modelo}

Seguindo Barro (1990), Barro e Sala-I-Martins (2004) e Aschauer (1989), supõe-se que a função de produção agregada per capita da economia pode ser expressa por:

$$
Y_{t}=A K_{t}^{\theta} H_{t}^{1-\theta} G_{t}^{\gamma}
$$

onde: A é um parâmetro de escala; $\theta$ e $\gamma$ são parâmetros não negativos, as variáveis agregadas, no instante $t, Y, H, K e$ Gão, respectivamente, em termos per capita, o produto ou renda total, o número de horas trabalhadas, o agregado dos estoques de capitais pertencentes ao setor privado $(K p)$ e empresas estatais $(K g)$ e o estoque de capital da administração pública ou infraestrutura, onde a expressão $G^{\gamma}$ representa o efeito deste capital sobre a produtividade total dos fatores, cuja intensidade é determinada pelo parâmetro $\gamma$. Esta especificação segue de perto Ferreira e Nascimento (2005), que também assumem retornos constantes de escala para os fatores privados, adotando a suposição de Turnovsky e Fisher (1995) e Glomm e Ravikumar (1994,1997).

Assume-se que a firma representativa por meio da função de produção, em cada instante $t$, escolhe os níveis de trabalho $(H)$ e capital $(K)$, de forma a maximizar seu lucro, tomando como dados preços e a oferta de infraestrutura per capita da economia G. Supõe-se, ainda, que um único bem é produzido através de um único processo produtivo. Com efeito, a firma representativa descreve a média das atividades produtivas em curso na economia, incluindo, portanto, processos produtivos públicos e privados.

O problema da firma representativa, para cada período t é:

$$
\max _{H t, K t}\left(Y_{t}-w_{t} H_{t}-r_{t} K_{t}\right)
$$

dados os preços $w_{t}$, o salário por hora trabalhada, e $r_{t}$, a taxa de aluguel do capital.

Supõe-se um consumidor representativo que vive infinitos períodos e, em cada período t, é dotado de uma unidade de tempo disponível para o trabalho $\left(h_{t}\right)$ e lazer $\left(1-h_{t}\right)$, extrai utilidade, além do lazer, do consumo $c_{t}$ e oferta de serviços públicos expressos por $C g_{\mathrm{t}}$, com 
uma taxa de desconto intertemporal $\beta$ entre 0 e 1 , de acordo com a expressão:

$$
\sum_{t=0}^{\infty} \beta^{t} U\left(c_{t}, C g t,\left(1-h_{t}\right)\right)
$$

cuja função utilidade a cada instante do tempo t, é, por hipótese dada por:

$$
U\left(c_{t}, C g_{t},\left(1-h_{t}\right)\right)=\log \left(c_{t}+\mu(1-d c) C g_{t}\right)+\psi \log \left(1-h_{t}\right)
$$

onde os parâmetros $\mu$ e $\psi$ medem, respectivamente, como o consumidor valoriza o consumo público per capita $\left(\mathrm{Cg}_{\mathrm{t}}\right)$ com relação ao consumo privado $\left(c_{t}\right)$, (ver Aschauer, 1985; Barro, 1981; Christiano; Eichembaum, 1992), e a importância relativa do lazer $\left(1-h_{t}\right)$ vis-à-vis este consumo. No presente modelo, o consumo público é passível de desvios, representados pela parcela $d c$. Salienta-se que, em geral, as escolhas individuais são representadas por letras minúsculas, enquanto as maiúsculas expressam variáveis agregadas per capita.

Por suposição, no período $t$, o consumidor representativo é dotado de estoque acumulado de capital $\left(k p_{t}\right)$ e suas rendas são compostas de renda do aluguel às firmas deste estoque de capital $\left(r_{t} k p_{t}\right)$, da renda do trabalho ofertado às firmas $\left(\mathrm{w}_{\mathrm{t}} \mathrm{h}_{\mathrm{t}}\right)$, renda proveniente de sua participação no retorno do capital das estatais $\left(\alpha_{t} r_{t} k g_{t}\right)$, rendimentos pela posse de títulos públicos $\left(\rho_{t} b_{t}\right)$, além de transferências líquidas recebidas do governo $\left(t r_{t}\right)$. Ademais, todas estas fontes de renda, inclusive rendimentos pela posse do estoque de dívida pública, $b_{t}$, exceto transferências, são taxadas pelo governo e a renda disponível em cada instante $t$, é gasta em consumo $\left(c_{t}\right)$, investimentos em bens de capital $\left(i p_{t}\right)$ e aquisição de títulos públicos $\left(b_{t+1}\right)$. Assim, a restrição orçamentária da família representativa consiste, em $t$, da seguinte expressão:

$$
\begin{gathered}
\left(1+\tau c_{t}\right) c_{t}+i p_{t}+b_{t+1}-b_{t}=\left(1-\tau h_{t}\right) w_{t} h_{t}+\left(1-\tau k p_{t}\right) r_{t} k p_{t}+ \\
\alpha_{t}\left(1-\tau k g_{t}\right) r g_{t} k g_{t}+\left(1-\tau b_{t}\right) \rho_{t} b_{t}+t r_{t}+d r_{t}
\end{gathered}
$$

onde $\tau c_{t}, \tau h_{t}, \tau k_{t}, \tau b_{t}$ são taxas impostas pelo governo e $d r_{t}$ é a renda proveniente de corrupção nos investimentos e gastos públicos reintroduzida no agregado da economia como renda recebida pela família. Por hipótese, $d r_{t}$ é gerada a partir de $d j r$, parcela dos investimen- 
tos per capita da administração pública $\left(J_{t}\right)$ desviada por corrupção, dir, parcela dos investimentos per capita das estatais $\left(I g_{t}\right)$ desviada por corrupção e a parcela $d c r$ decorrente de desvios no consumo per capita do governo $\left(\mathrm{Cg}_{t}\right)$, ou seja:

$$
d r_{t}=\operatorname{djrJ}_{t}+\operatorname{dirIg} g_{t}+\operatorname{dcr} C g_{t}
$$

Admite-se, ainda, que o consumidor conheça as leis de movimento do seu estoque de capital $(\mathrm{kp})$ e dos estoques, per capita, de capital privado $(K p)$, das estatais $(K g)$ e da infraestrutura $(G)$ :

$$
\begin{aligned}
& k p_{t+1}=(1-\delta) k p_{t}+i p_{t} \\
& K p_{t+1}=(1-\delta) K p_{t}+I p_{t} \\
& K g_{t+1}=(1-\delta) K g_{t}+(1-d i) I g_{t} \\
& G_{t+1}=(1-\delta g) G_{t}+(1-d j) J_{t}
\end{aligned}
$$

onde $\delta$ e $\delta g$ são taxas de depreciação dos estoques de capital, Ip é o investimento privado agregado per capita e, seguindo Gomes; Ellery Jr; Bugarin (2002), Gupta et al. (2011) e Dabra-Norris et al. (2011), que adotaram uma regra de acumulação de capital considerando a possibilidade de parcela do investimento público ser improdutiva ou desviada, introduz-se nas equações de acumulação parcelas de desvios, nos investimentos das estatais, di, e investimentos da administração pública, $d j$.

Admite-se, portanto, que os recursos destinados aos investimentos públicos não são completamente transformados em capital, existindo graus de ineficiência e/ou corrupção, expressos nas equações acima por $d j$ e $d i$, que afetam os níveis de capitais públicos acumulados. Considerações econômicas dessa natureza foram abordadas inicialmente por Pritchet (2000), o qual observa que o método do estoque de capital perpétuo apresenta problemas, principalmente para países em desenvolvimento, ao negligenciar o fato que o custo do investimento público não é o incremento para o valor do capital público, alegando que, diferentemente do investimento privado, não era plausível admitir que todo dólar que o setor público gastava em investimento transformava-se em capital avaliado economicamente. Seguindo essa mesma linha de argumentação, Gomes, Ellery Jr. 
e Bugarin (2002), partem de uma regra de acumulação na qual se especifica um parâmetro de desperdício diretamente sobre os investimentos públicos e estimam este parâmetro para os investimentos públicos no Brasil da ordem de 20\%, mostrando, assim, que o acréscimo ao valor do estoque de capital público (da administração pública e das estatais) não corresponde ao valor do investimento público (administração pública e empresas estatais) a ele associado. Nessa linha, cita-se, ainda, para contextualizar o desperdício ou desvio existente na esfera pública, embora com um enfoque de microdados para a economia italiana, Bandiera et al. (2009), que separa o desperdício em ativo, decorrente de práticas corruptas, e passivo, inerente à ineficiência, encontrando estimativa que o desperdício passivo é bem maior que o ativo, em média $82 \%$ do desperdício total.

Importa salientar que o desperdício pode ser composto tanto por ineficiência produtiva na realização do gasto como por corrupção ou por ambos. O fato é que há um alto grau de desperdícios que muitas vezes distorcem os efeitos dos gastos públicos em investimentos sobre a acumulação de capital. Provavelmente, parte significativa do desperdício está atrelada à corrupção, ou seja, agentes públicos, sozinhos ou em conluio, valendo-se do seu cargo, atuam desviando recursos para si ou para outrem.

O modelo admite que haja uma renda proveniente de corrupção reintroduzida na economia como uma renda recebida pelas famílias que, em termos per capita, algebricamente corresponde a:

$$
D R_{t}=\operatorname{djr} J_{t}+\operatorname{dir} \operatorname{Ig}_{t}+\operatorname{dcr} C g_{t}
$$

onde $D R_{t}$ é o total da renda desviada que é transferida para as famílias, sendo djr a parcela desviada dos recursos destinados aos gastos com investimentos da administração pública, dir a parcela desviada dos gastos destinados aos investimentos da estatais e $d c r$ a parcela desviada dos gastos destinados à oferta de bens públicos.

Por fim, no modelo supõe--se: $d j r \leq d j, d i r \leq d j$ e $d c r \leq d c$. O que procura admitir que nem todo desvio ocorrido corresponde à renda de corrupção, havendo a possibilidade de configurar puro desperdício por ineficiências do setor público. 
A restrição orçamentária do governo em t é dada por:

$$
C g_{t}+J_{t}+I g_{t}+T R_{t}+\rho_{t} B_{t}=B_{t+1}-B_{t}+T_{t}+\left(1-\alpha_{t}\right)\left(1-\tau k g_{t}\right) r g_{t} k g_{t}
$$

onde, em termos per capita, no momento $t, B_{t}$ é o estoque da dívida, $(1-\alpha t)\left(1-\tau \mathrm{kg}_{t}\right) r_{t} t K g_{t}$ é a fração destinada ao governo da receita, líquida de impostos, do aluguel do capital das empresa estatais, $T R_{t}$ são transferências líquidas do governo às famílias e $T_{t}$ corresponde à arrecadação tributária expressa por:

$$
\mathrm{T}_{\mathrm{t}}=\tau c_{t} C_{t}+\tau h_{t} w_{t} H_{t}+\tau k p_{t} r_{t} K p_{t}+\tau k g_{t} r_{t} K g_{t}+\tau b_{t} \rho_{t} B_{t}
$$

sendo o conjunto de alíquotas de impostos $\tau_{t}=\left\{\tau c_{t}, \tau h_{t}, \tau k p_{t}, \tau \mathrm{kg}_{t}\right.$, $\left.\tau b_{t}\right\}$, composto, respectivamente, por alíquotas de impostos sobre o consumo, sobre o trabalho, sobre os capitais privados e das estatais e sobre a dívida pública, define-se uma política fiscal, no momento $t$, através do conjunto: $\left\{\tau_{t}, \alpha_{t}, \alpha c_{t}, \alpha j_{t}, \alpha i_{t}, \alpha b_{t}\right\}$ tal que: $\alpha c_{t}=\mathrm{Cg}_{t} / Y_{t}$ (fração do consumo do governo em relação ao produto no momento t).; $\alpha j_{t}=J_{t} / Y_{t}$ (fração do investimento da administração pública, exceto estatais, em relação ao produto no momento t) $\alpha i_{t}=I g_{t} / Y_{t} \alpha i_{t}$ (fração do investimento das estatais em relação ao produto no momento $t$ ) e $\alpha b_{t}=B_{t} / Y_{t}$ (fração da dívida pública líquida do governo em relação ao produto no momento $\mathrm{t}$ ).

\section{Definição de equilíbrio}

Dada a política fiscal do governo $\left\{\tau c_{t}, \tau h_{t}, \tau k p_{t}, \tau k g_{t}, \tau b_{t}, \alpha, \alpha c_{t}, \alpha j_{t}\right.$, $\left.\alpha i_{t}, \alpha b_{t}\right\}^{\infty}{ }_{t=0} \mathrm{e}$ as parcelas de desvios e corrupção, um equilíbrio competitivo é uma coleção de sequências de decisões das famílias $\left\{c_{t}\right.$, ipt, $\left.h_{t}, b_{t+1}\right\}^{\infty}{ }_{t=0}$, uma sequência de estoques per capita de capitais públicos e privado $\left\{K p_{t}, K g_{t}, G_{t}\right\}^{\infty}{ }_{t=0}$ e uma sequência de preços $\{w t$, $r t, \rho t\}^{\infty}{ }_{t=0}$, tais que:

(i) a sequência $\left\{c_{t}, i p_{t}, h_{t}, b_{t+1}\right\}^{\infty}{ }_{t=0}$, resolve o problema de maximização de utilidade do consumidor representativo;

(ii) Os preços dos fatores são determinados por:

$$
w_{t}=(1-\theta) A K^{\theta} H^{-\theta}{ }_{t} G^{\gamma}{ }_{t}
$$




$$
r_{t}=\theta A K^{\theta-1}{ }_{t} H^{1-\theta}{ }_{t} G^{\gamma}{ }_{t}
$$

onde $\quad K_{t}=K p_{t}+K g_{t} ;$

(iii) os mercados se equilibram:

$$
\begin{aligned}
& \mathrm{c}_{\mathrm{t}}=C_{t} ; \quad i p_{t}=I p_{t} ; k p_{t}=K p_{t} ; b_{t}=B_{t} ; h_{t}=H_{t} ; k g_{t}=K g_{t} ; t r_{t}= \\
& T R_{t} ; d r_{t}=D R_{t}
\end{aligned}
$$

(iv) a restrição de recursos da economia é atendida:

$$
C_{t}+I p_{t}+(1-d c r) C g_{t}+(1-d i r) I g_{t}+(1-d j r) J_{t}=A K^{\theta}{ }_{t} H^{1-\theta}{ }_{t} G_{t}{ }_{t}
$$

(v) a restrição orçamentária do governo é atendida em todo instante t.

\section{Calibração}

O objetivo desta seção consiste em calibrar os parâmetros de forma a compatibilizar a solução estacionária do modelo e os dados observados para a economia brasileira, supondo que esta economia esteja em trajetória estacionária. ${ }^{5}$

A partir das Contas Nacionais do Brasil para o ano de 2010, divulgadas pelo IBGE, obtém-se os valores dos parâmetros de política fiscal para consumo do governo, investimento das estatais e investimento da administração pública, todos com relação ao PIB, os quais correspondem, respectivamente a: $\alpha c=\mathrm{Cg} / Y=0,2117 ; \alpha i=I g / Y=0,0229$; $\alpha j=J / Y=0,0257$. Para o valor do parâmetro fiscal relativo ao endividamento público, $\alpha b$, considera-se a dívida líquida do setor público (governos federais, estaduais, municipais, estatal e previdência social), calculada pelo Banco Central do Brasil - Bacen, também com relação ao PIB, $\alpha b=B / Y$, o que perfaz um valor da ordem de 0,4016 em 2010. A taxa de desconto intertemporal, $\beta$, é obtida a partir da condição de primeira ordem das famílias para escolha do nível de dívida em estado estacionário, $1+(1-\tau \mathrm{b}) \rho=1 / \beta$, bastando para isso

5 Dados os parâmetros de desvios, de preferências e tecnológicos, define-se uma solução estacionária do modelo como aquela caracterizada por trajetórias temporais invariantes para parâmetros de política fiscal e variáveis endógenas do modelo. 
determinar valores para $\tau b$, taxação sobre a dívida pública, e $\rho$, remuneração real da dívida pública.

Para encontrar $\tau b$ segue-se a legislação dos impostos retidos na fonte incidentes sobre as aplicações financeiras (imposto de renda e imposto sobre operações financeiras-IOF), no caso, a Lei $n^{\circ} 11.033 / 2004$, a qual, para o imposto de renda, define uma faixa regressiva de $22,5 \%$ a $15 \%$ de acordo com o tempo de aplicação $(22,5 \%$ até 180 dias, $20 \%$ de 181 a 360 dias, $17,5 \%$ de 361 a 720 dias e $15 \%$ acima de 720 dias) e para o IOF institui uma alíquota de $1 \%$ ao dia sobre o rendimento dos títulos cujo resgate seja inferior a 30 dias após a compra (se vender o título após 30 dias o valor do IOF é zero). De acordo com o Relatório Mensal da Dívida Pública da Secretaria do Tesouro Nacional, posição dezembro de 2010, o prazo de vencimento da dívida pública mobiliária federal (interna) é 12 meses para 24,57\% dos títulos, 1 a 2 anos para 20,49\% da dívida e acima de 2 anos para o resto da dívida. Em vista disso, encontra-se uma alíquota média ponderada de $17,05 \%$ para o imposto de renda e de zero para o IOF, obtendo-se um $\tau b$ de 0,1705 .

Dado que, segundo o Boletim Anual do Banco Central de 2010, medidos em relação ao PIB, a razão entre o total dos pagamentos dos juros da dívida líquida do setor público, 0,0532, e a dívida líquida, 0,4016 , correspondente a $13,24 \%$, é uma estimativa média da taxa de juros nominais. Excluindo-se a taxa de inflação do período de 5,91\% (medida pelo IPCA de 2010 divulgado pelo IBGE), obtém-se uma estimativa para a taxa média de juros real da economia, $\rho$, de 0,0692 . Assim, obtidos os valores de $\tau \mathrm{b}=0,1705$ e $\rho=0,0692$, encontra-se um valor de 0,9457 para o parâmetro $\beta$.

Dado que $\mathrm{G}_{t+1}=(1-\delta g) \mathrm{G}_{t}+(1-\mathrm{dj}) \mathrm{J}_{t}$ é a equação da acumulação do capital da administração pública, em estado estacionário obtém-se a depreciação do capital governamental de $\delta g=((1-\mathrm{dj})(\mathrm{J} / \mathrm{G})$. O valor de $\mathrm{J} / \mathrm{G}=0,057$ é determinado pela relação investimento da administração pública e capital público, ambos em relação ao PIB, calculados a partir dos dados disponibilizados pelo IPEADATA e pelo FINBRAS/ STN/MF, para 2008. Para a parcela de investimento da administração pública desperdiçada, dj, utiliza-se a taxa encontrada por Gomes; Ellery Jr e Bugarin (2002) para o total de desvios nos investimentos (ineficiência, corrupção, entre outras) de $20 \%$. Para $d j=0,2$ tem-se uma depreciação para o capital público de 0,0456 , valor próximo 
aos utilizados por Ferreira e Nascimento (2005) e Pereira e Ferreira (2008 e 2011), respectivamente, cerca de 6\% e 5\%.

Dado que, de acordo com o modelo, respectivamente, tem-se as seguintes equações de acumulação de capital para o setor privado e estatais, $K g_{t+1}=(1-\delta) K g_{t}+(1-d i) I g_{t}$ e $K p_{t+1}=(1-\delta) K p_{t}+I p_{t}$, em estado estacionário, a soma destes estoques torna-se $K p+K g=K=((1-d i)$ $I g+I p)) / \delta$. Portanto, a taxa de depreciação pode ser obtida a partir da seguinte expressão, $\delta=((1-d i)(I g / Y)+(I p / Y)) /(K / Y)$. No cálculo desta taxa de depreciação utilizam-se informações relativas aos estoques de capitais disponíveis no IPEADATA para 2008 (último ano divulgado), além de dados para investimentos privados e das estatais disponíveis nas contas nacionais (IBGE) e DEST/MPOG, também, para o mesmo ano. Para $K / Y$ tem-se 1,878 , enquanto, para $I p / Y$ e $I g / Y$, respectivamente, 0,1722 e 0,0176 , o que determina $\delta=0,0992$, admitindo-se desvios relacionados aos investimentos das estatais, $d i$, na mesma dimensão dos supostos para os investimentos da administração pública, $d j$.

Uma vez que o modelo determina que a renda do trabalho como fração do produto é constante, ou seja, que $w H / Y=(1-\theta)$. Admitindo-se que esta fração seja 0,5771 , o que corresponde à soma da remuneração dos empregados adicionada a dois terços do rendimento misto bruto (renda dos autônomos) em relação ao PIB (excluindo-se impostos e subsídios sobre a produção), obtidos da Conta de Geração da Renda divulgada pelo IBGE para 2009, obtém-se um valor de $\theta=0,4229$.

Os parâmetros tributários $\tau c, \tau h, \tau k p$, $\tau k g$ são calculados a partir das contas nacionais, divulgadas pelo IBGE, dos dados da arrecadação tributária no Brasil constantes da Nota Técnica no 16 da Diretoria de Estudos e Políticas Macroeconômicas do IPEA, março de 2010, e do Relatório Anual "Carga Tributária no Brasil 2010 - Análise por tributo e base de incidência", da Secretaria da Receita Federal do Brasil - RFB/MF. Inicialmente, classificou-se os tributos em três categorias, conforme segue abaixo:

a) Tributação sobre o trabalho: FGTS + Salário Educação + Sistema S + Contribuição Previdenciária (pública e privada);

b) Tributação sobre o consumo: ICMS + IPI + ISS + II + CIDE 
c) Tributação sobre o retorno do capital e títulos públicos: IRPJ + CSLL + IRPF + COFINS + PIS/PASEP + IPTU + IPVA + IOF + ITR + outros. ${ }^{6}$

Dessa forma, obteve-se as seguintes participações dos tributos pagos com relação ao produto interno bruto, exercício 2010, apresentadas no Quadro 1.

Quadro 1 - Participações de rendas tributárias no Brasil em relação ao PIB

\begin{tabular}{|l|c|}
\hline Rendas tributárias em relação ao PIB & $\%$ \\
\hline Tributação sobre o consumo & 9,57 \\
\hline Tributação sobre o trabalho & 9,30 \\
\hline Tributação sobre o retorno do capital e títulos públicos & 14,76 \\
\hline Carga tributária total & 33,63 \\
\hline
\end{tabular}

Fonte: Elaboração própria a partir dos dados do Relatório Anual "Carga Tributária no Brasil 2010 - Análise por tributo e base de incidência", da Secretaria da Receita Federal do Brasil - RFB/MF.

O parâmetro tributário sobre o consumo, $\tau c$, é calculado a partir da relação dos impostos pagos sobre o consumo em relação ao PIB, $9,57 \%$, e a fração do consumo no PIB ( $C / Y=60,57 \%)$, obtendo-se $15,79 \%$ como alíquota da tributação sobre o consumo.

Para a alíquota de rendimentos do trabalho, obteve-se a razão entre o total de tributos pagos sobre rendimentos de trabalhos com relação ao $\mathrm{PIB}, 9,30 \%$, e a fração da renda do trabalho no produto, $w H / Y=(1-\theta)=0,5771$, determinando-se $\tau h=16,11 \%$.

Uma vez que as tributações sobre os retornos dos capitais, $\tau k p r p K p$ e $\tau k g$ rg $K g$, e títulos públicos, $\tau b \rho B$, em relação ao $\mathrm{PIB}$, encontramse agregadas no Quadro 1, optou-se por extrair a tributação sobre títulos da seguinte maneira. Dado que, segundo o Boletim Anual do Banco Central de 2010, o total dos pagamentos dos juros da dívida líquida do setor público, em relação ao PIB, em 2010 correspondia a 0,05316 e, conforme calibragem acima, admitindo-se que a correspondente alíquota sobre estes rendimentos situa-se em 0,1705, o produto destes valores perfaz 0,0091, o que seria a fração da carga

${ }^{6}$ Como os automóveis não utilizados em processos produtivos não compõem o estoque de capital, uma vez que são considerados bens de consumo duráveis nas contas nacionais, incluir toda a arrecadação do IPVA no cálculo da alíquota de capital gera uma pequena distorção, já que o IPVA recolhido sobre estes bens deveria compor a tributação sobre o consumo. Porém, como a arrecadação desse imposto corresponde a apenas cerca de $0,5 \%$ do PIB, este procedimento não deve afetar as alíquotas calibradas de maneira significativa. 
tributária referente aos rendimentos de títulos públicos. A extração deste valor do agregado, 14,76\%, expresso no Quadro 1, produz uma estimativa da tributação dos rendimentos sobre os capitais em relação ao PIB de 13,84\%. Em estado estacionário, a carga tributária sobre rendimentos de capital corresponde a ( $\tau k p r p ~ K p+\tau k g ~ r g ~ K g) / Y$, ou, admitindo-se $\tau k p=\tau k g$, simplesmente, $\tau \mathrm{kp}(\mathrm{rpKp}+\mathrm{rgKg}) / \mathrm{Y}$, como, segundo o modelo, $(r p K p+r g K g) / Y=\theta$, a tributação dos rendimentos sobre os capitais em relação ao PIB de 13,84\% implica uma alíquota sobre o capital $\tau k p=0,1384 / \theta=0,3275$, dado $\theta=0,4229$, acima calibrado.

Para encontrar a participação privada no excedente operacional bruto das empresas estatais, parâmetro $\alpha$, utilizam-se dados divulgados pela Secretaria do Tesouro Nacional do Ministério da Fazenda - STN/MF quanto às participações acionárias da União, posição de dezembro de 2010. ${ }^{7}$ O parâmetro é obtido a partir da média ponderada da participação acionária do governo federal pelo valor do capital integralizado, que é a realização em valores e/ou bens do capital subscrito (capital previsto no estatuto social da empresa). Considerando as 23 sociedades de economia mista (Petrobrás, Eletrobrás, Telebrás, Banco do Brasil, Banco do Nordeste do Brasil, Instituto de Resseguros do Brasil, entre outras) e as 21 empresas públicas (BNDES, CEF, ECT, SERPRO, entre outras), que a União detém participação majoritária, encontrou-se uma média ponderada equivalente a $62,87 \%$ na participação acionária. Desta maneira, utiliza-se o complementar deste valor, ou seja, 37,13\%, como proxy para $\alpha$, participação privada no excedente operacional bruto das empresas estatais.

O valor do parâmetro $\mu$, que mede quanto o indivíduo valoriza o consumo público relativamente ao privado, para Barro (1981) pode variar entre zero e algo próximo a 1. Aschauer (1985) estimou $\mu$ entre 0,23 e 0,43 para a economia americana. Christiano e Eichembaum (1992) fixaram esse parâmetro em 1 e 0 para fins de verificar efeitos dos gastos governamentais em modelos de ciclo reais de negócios. Ferreira e Nascimento (2005) utilizam $\mu=0,5$ como um benchmark, mas realizam uma análise de sensibilidade verificando o comportamento do produto e do bem-estar para $\mu=0$ (há desperdício do gasto público) e $\mu=1,0$ (valorizam-se igualmente os dois tipos de consumo). A priori, considerando-se a extensão de variação no valor

disponível em: www.tesouro.fazenda.gov.br/haveres_uniao/downloads/participacao_acionaria.pdf. 
do parâmetro, de acordo com estes autores, no intervalo entre zero e 1, optou-se admitir $\mu=0,5$, valor utilizado por Ferreira e Nascimento (2005) para o caso da economia brasileira no seu modelo básico.

Para a intensidade da externalidade do capital público, $\gamma$, ou seja, a elasticidade do produto com relação ao capital público, Aschauer (1989) estimou valores entre 0,35 e 0,45 para a economia americana. Ferreira e Maliagros (1999) estimaram um valor de 0,4 para a economia brasileira. Entretanto, considerandose que as estimativas de Aschauer (1989) apresentam problemas metodológicos de estimação, direção de causalidade entre investimento público e privado, estacionaridade das séries e correlação espúria (ver Munnell, 1992), e que parte do capital pertencente ao governo, o capital das estatais, está adicionado ao capital privado na função de produção agregada do modelo, optou-se por admitir $\gamma=0,09$, valor médio estabelecido por Ferreira e Nascimento (2005), a partir de estimativas para a economia brasileira obtida por diferentes autores, utilizando função de produção semelhante a suposta no modelo.

Para a importância relativa do lazer vis-à-vis o consumo, $\psi$, peso do lazer na função utilidade, segue-se Cooley e Prescott (1995), bem como Gomes, Ellery Jr. e Bugarin (2002), Kanczuk (2002) e Mussolini (2011), que determinam $\psi$ a partir da hipótese de que o agente dedica cerca de um terço do seu tempo disponível ao processo produtivo. Assim, supondo $\mathrm{H}=1 / 3$ em estado estacionário, encontrase $\psi=1,2109$.

Admite-se que o valor do parâmetro relacionado ao desvio ou desperdício no consumo do governo, $d c$, seja igual aos valores de $d i$ e $d j$, admitidos iguais a 0,20 , tendo em vista que tanto o orçamento de investimento das empresas estatais como o orçamento fiscal, que compõem a lei orçamentária anual, são elaborados e executados (por meio de funcionários e empregados públicos) pelo poder executivo e aprovados pelo poder legislativo, sendo esse processo decisório/ aprovativo de alocação de recursos sujeito aos mesmos problemas de agente-principal e deficiências institucionais, que normalmente explicam os desvios relativos à corrupção e à ineficiência dos gastos públicos. 
Conforme o modelo proposto, em termos per capita, há na restrição orçamentária da família representativa renda proveniente de corrupção, $D R$, composta por dirIg, parcela recebida pelas famílias decorrente de desvios ocorridos nos investimentos das estatais, djrJ, parcela recebida devido a desvios nos investimentos da administração pública, e $d c r C g$, parcela recebida decorrente de desvios nos gastos de consumo do governo. Salienta-se que, se, para todo $\mathrm{t}, D R_{\mathrm{t}}=0$ isto não implicaria a inexistência de parcelas de desvios de corrupção nos desvios $(d j, d c, d i)$, mas sim que todo o recurso desviado de corrupção seria evadido e não internalizado na economia. ${ }^{8}$ Supondo toda a renda da corrupção internalizada na economia, necessita-se determinar valores para os parâmetros dir, djr e dcr.

Como já foi definido $d i=d j=d c=0,20$, assim, dir, djr e $d c r$ devem ser menores que 0,20 , supondo que existem ineficiências ou desperdícios nos dispêndios públicos. Os valores dos parâmetros dir, djr e dcr são deduzidos a partir de estimativas. Supondo $d i r=d j r$, considera-se o valor de 9,5\% para estes parâmetros, correspondente à média das estimativas de Hobbs (2005), TCU (2011) e FIDIC (2012). Quanto à corrupção relacionada aos gastos correntes (consumo do governo, basicamente aquisição de bens e contratação de serviços), admitese $d c r$ igual $11 \%$, valor aproximado à média entre as estimativas de Ferraz e Finan (2007), Di Tella e Schargrosky (2004), que é de $10,75 \% .^{9}$

O parâmetro $A$ afeta apenas o tamanho ou escala da economia e é normalizado de forma que o valor do produto em estado estacionário seja igual a 100 .

Os parâmetros calibrados estão resumidos nos quadros a seguir:

Quadro 2 - Parâmetros de preferência e tecnológicos

\begin{tabular}{|c|c|c|c|c|c|c|}
\hline$\beta$ & $\mu$ & $\psi$ & $\theta$ & $\delta$ & $\delta \mathrm{g}$ & $\gamma$ \\
\hline 0,9457 & 0,50 & 1,2109 & 0,4229 & 0,0992 & 0,0456 & 0,09 \\
\hline
\end{tabular}

Fonte: Elaboração própria.

8 Segundo Klitigaard (1994), a corrupção nunca é zero devido ao custo benefício de extinguila, apesar de poder ser controlada.

9 Ferraz; Finam (2007): 9\% do valor fiscalizado e Di Tella e Schargrosky (2004): 15\% durante o crackdown e depois $10 \%$. 
Quadro 3 - Parâmetros de política fiscal do governo

\begin{tabular}{|c|c|c|c|c|c|c|c|c|c|}
\hline$\alpha$ & $\alpha c$ & $\alpha j$ & $\alpha i$ & $\alpha b$ & $\tau C$ & $\tau H$ & $\tau K p$ & $\tau K g$ & $\tau B$ \\
\hline 0,3713 & 0,2117 & 0,0257 & 0,02290 & 0,4016 & 0,15799 & 0,1611 & 0,32759 & 0,32759 & 0,1705 \\
\hline
\end{tabular}

Fonte: Elaboração própria.

Quadro 4 - Parâmetro de desvios e corrupção

\begin{tabular}{|c|l|l|l|l|l|}
\hline \multicolumn{1}{|c|}{$d i$} & \multicolumn{1}{c|}{$d j$} & \multicolumn{1}{c|}{$d c$} & \multicolumn{1}{c|}{$d i r$} & \multicolumn{1}{c|}{$d j r$} & \multicolumn{1}{c|}{$d c r$} \\
\hline 0,20 & 0,20 & 0,20 & 0,095 & 0,095 & 0,11 \\
\hline
\end{tabular}

Fonte: Elaboração própria.

\section{Resultados}

Por hipótese, os desvios definidos no modelo podem ocorrer em três tipos de dispêndios: nos investimentos das estatais, di, nos investimentos da administração pública, $d j$, e no consumo da administração pública, dc. Além disto, ao se definir no modelo parcelas destes dispêndios geradoras de renda de corrupção através dos parâmetros de corrupção nos investimentos das estatais, dir, nos investimentos da administração pública, $d j r$, e no consumo público, $d c r$, definem-se as diferenças entre estes dois tipos de parâmetros como parâmetros, puramente, de ineficiência, ou seja, parcelas de ineficiências que podem ocorrer: nos investimentos das estatais, di-dir, nos investimentos da administração pública, $d j$-djr, e no consumo da administração pública, $d c-d c r$. Com efeito, a partir da calibragem dos parâmetros de desvios $(d j=d i=d c=0,2)$ e corrupção $(d i r=d j r=0,095$ e $d c r=0,11)$, admite-se ineficiências nos gastos do setor público da ordem de $10 \%$.

De acordo com os parâmetros calibrados, o volume de recursos obtidos a partir da corrupção (DR) corresponde a 2,79\% do produto, valor bastante inferior ao obtido por Carraro et al. (2006), de 11,30\% do PIB, mas muito próximo ao estimado por estudo da FIESP (2011) para o ano de 2010 , cerca de $2,30 \%$ do PIB. ${ }^{10}$

\footnotetext{
${ }^{10}$ Os valores encontrados no presente trabalho e em Carraro et al. (2006), têm significados semelhantes, na medida em que ambos podem ser definidos como "volume de recursos envolvidos com corrupção"; porém, as metodologias utilizadas são distintas, uma vez que em Carraro et al. (2006) não utiliza-se um modelo dinâmico de equilíbrio geral. Nesse sentido, considera-se que o presente trabalho contribui para a pesquisa na área por investigar, além dos efeitos de crescimento através de um modelo dinâmico, eventuais efeitos de bem-estar proporcionados por mudanças nos níveis de corrupção.
} 
No cenário básico, o consumo privado no modelo atinge $60,58 \%$ do produto, valor um pouco superior ao consumo em relação ao PIB divulgado pelo IBGE, 60,57\%, para o ano de 2010 , e o investimento privado se aproxima de $16,18 \%$, superior ao divulgado pelo IBGE para esse agregado, que é de $13,40 \%$, para o mesmo ano. No Quadro 5 , apresentam-se valores estacionários para variáveis selecionadas do modelo.

Quadro 5 - Valores estacionários no cenário básico

\begin{tabular}{|l|c|c|c|c|c|c|}
\hline Variáveis & $\mathrm{C}$ & $\mathrm{Cg}$ & $\mathrm{Ip}$ & $\mathrm{Y}$ & $\mathrm{H}$ & $\mathrm{DR}$ \\
\hline Valores Estacionários & 60,58 & 21,17 & 16,18 & 100 & 0,333 & 2,79 \\
\hline
\end{tabular}

Fonte: Elaboração própria.

Considerando-se eventuais modificações em parâmetros de corrupção e ineficiência dos gastos públicos é possível se verificar, a partir do modelo calibrado, como os agregados macroeconômicos desta economia evoluem ao longo do tempo e, através destas evoluções, mensurar possíveis ganhos ou perdas de bem-estar determinados por estas modificações. Assim, o objetivo desta seção é realizar exercícios contrafactuais considerados relevantes para a compreensão de como a corrupção e a ineficiência do setor público no Brasil distorcem as decisões dos agentes e afetam o nível de eficiência ou bem-estar do agregado da economia.

Seguindo Lucas (1987) e Cooley e Hansen (1991), bem como Pereira e Ferreira (2010, 2011), diante de um choque inesperado, o ganho de bem-estar ou aumento da eficiência do agregado da economia pode ser mensurado a partir do percentual constante de mudança no consumo, $x$, relativo aos níveis correspondentes ao cenário básico (CB) para todos os momentos do tempo, t, mantidas as horas de trabalho e consumo do governo nos níveis deste cenário, requerido para manter o nível de utilidade igual àquele que seria obtido após a ocorrência do choque ou experimento de cenário alternativo (CA). Valores positivos (negativos) de $x$ indicam que o experimento do cenário alternativo seria equivalente a uma elevação (redução) percentual permanente nos níveis de consumo determinados pelo cenário básico, supondo tudo mais constante. 


\subsection{Eliminação da corrupção e/ou ineficiência: efeitos macroeconômi- cos e de bem-estar}

Supondo a inexistência de correlações entre determinantes de corrupção e níveis de ineficiência, admite-se, inicialmente, que seria possível reduzir ou eliminar corrupções (ineficiências) nos gastos públicos sem que isto afetasse os níveis de ineficiência (corrupção) nestes gastos.

Nesta hipótese, como primeiro exercício contrafactual, ver Simulação 1 no Quadro 6, verificam-se quais seriam os efeitos macroeconômicos e de bem-estar da completa eliminação da ineficiência e corrupção nos gastos públicos. Os resultados indicam que, no longo prazo, têm-se efeitos positivos consideráveis, os investimentos privados se elevam, bem como as horas trabalhadas, impactados pela melhoria da eficiência, o produto aumenta significativamente, sendo sua trajetória, no novo estado estacionário, quase 4,5\% superior à trajetória determinada por seu estado estacionário inicial. A medida de bem-estar, $x$, corresponde a 1,26\%, indicando que este cenário alternativo implicaria ganhos de eficiência equivalentes a um aumento permanente de $1,26 \%$ nos atuais níveis de consumo, mantidos os valores estacionários, anteriores ao choque, para as demais variáveis. A magnitude de importância deste ganho de bem-estar é evidente, comparada aos ganhos de suavização dos ciclos nos Estados Unidos, em torno de 0,1\% do consumo total, indicada por Lucas (1987) ou ganhos de uma reforma tributária no Brasil que reduzisse taxação sobre o investimento e renda dos fatores, aumentando compensatoriamente impostos sobre o consumo, da ordem de $0,6 \%$, de acordo com estimava de Araújo e Ferreira (1999). Sendo comparável ao ganho de bem-estar de 1,8\%, com igual metodologia, encontrado por Pereira e Ferreira (2008) para a política de Parceria Público-Privada no Brasil.

No curto prazo, a redução do investimento observada no Quadro 6 pode ser atribuída à eliminação da ineficiência, pois antes era necessário investir mais para compensar ineficiências nos gastos governamentais. Este resultado, também observado no caso da Simulação 2, a seguir, deve-se à mesma razão.

Na Simulação 2 (Quadro 6) são eliminadas as ineficiências nos investimentos e gastos de consumo público, mantendo-se a corrupção total, e verifica-se que o consumo, os investimentos, o produto e as 
horas trabalhadas sofrem reduções no curto prazo. Contudo, no longo prazo, ocorre aumento razoável no consumo, 1,3\%, e um aumento leve do produto, 0,92\%, aumento inferior ao obtido na Simulação 1, indicando haver uma relação negativa entre corrupção e crescimento do produto. O nível de bem-estar, entretanto, sofre um acréscimo de $2,46 \%$, superior ao obtido no experimento anterior.

Em relação à Simulação 3, mantêm-se as ineficiências, mas neste experimento todos os tipos de corrupção supostos no modelo são eliminados e o resultado encontrado indica uma queda no nível de bem -estar equivalente a $-1,17 \%$. Este resultado indica que a corrupção estaria corrigindo alguma distorção presente nesta economia. Quanto aos efeitos deste experimento sobre os agregados macroeconômicos, conforme indica a literatura anteriormente citada, verifica-se uma relação inversa entre corrupção e níveis de investimentos privados e produto. A razão está no fato de a renda de corrupção, ao ser reduzida, elevar o número de horas trabalhadas, o que eleva o retorno do capital e consequentemente induz aumentos do investimento e produto.

Para investigar a origem da distorção que o modelo indica estar sendo reduzida através da existência de corrupção, realizam-se experimentos de eliminação da corrupção isoladamente nos investimentos da administração pública e estatais, bem como nos gastos de consumo do governo. 
Quadro 6 - Simulações supondo não haver substitutibilidade entre corrupção e ineficiência $^{11}$

\begin{tabular}{|c|c|c|c|c|c|c|c|c|c|c|c|}
\hline \multirow{3}{*}{ SIMULAÇÕES } & \multicolumn{11}{|c|}{ Variações Percentuais em Variáveis Selecionadas } \\
\hline & \multicolumn{2}{|c|}{ C } & \multicolumn{2}{|c|}{ Ip } & \multicolumn{2}{|c|}{$Y$} & \multicolumn{2}{|c|}{$\mathrm{Cg}$} & \multicolumn{2}{|r|}{$\mathrm{H}$} & \multirow{2}{*}{$\begin{array}{l}\text { Bem- } \\
\text { Estar }\end{array}$} \\
\hline & $\mathrm{CP}$ & LP & $\mathrm{CP}$ & LP & $\mathrm{CP}$ & LP & $\mathrm{CP}$ & LP & CP & LP & \\
\hline $\begin{array}{l}\text { Simulação } 1 \text { - elimina corrupção e } \\
\text { ineficiência }\end{array}$ & $-3,59$ & 0,44 & $-3,63$ & 1,50 & 0,04 & 4,46 & 0,04 & 4,46 & 0,07 & 0,2 & 1,26 \\
\hline $\begin{array}{l}\text { Simulação } 2 \text { - elimina ineficiência } \\
\text { mantendo corrupção }\end{array}$ & $-0,01$ & 1,32 & $-3,87$ & 0,58 & $-0,80$ & 0,93 & $-0,80$ & 0,93 & $-1,38$ & $-1,11$ & 2,46 \\
\hline $\begin{array}{l}\text { Simulação } 3 \text { - elimina corrupção } \\
\text { mantendo ineficiência }\end{array}$ & $-3,53$ & $-1,46$ & 4,28 & 3,28 & 1,81 & 3,29 & 1,81 & 3,29 & 3,17 & 2,76 & $-1,17$ \\
\hline $\begin{array}{l}\text { Simulação } 4 \text { - elimina somente a } \\
\text { corrupção no investimento da ad- } \\
\text { ministração pública }\end{array}$ & $-0,22$ & 1,96 & $-0,17$ & 2,38 & 0,12 & 2,38 & 0,12 & 2,38 & 0,19 & 0,23 & 0,43 \\
\hline $\begin{array}{l}\text { Simulação } 5 \text { - elimina somente a } \\
\text { corrupção no investimento estatal }\end{array}$ & CT & CT & $-1,35$ & $-1,35$ & CT & CT & CT & CT & CT & CT & zero \\
\hline $\begin{array}{l}\text { Simulação } 6 \text { - elimina somente a } \\
\text { corrupção no consumo do governo }\end{array}$ & $-3,40$ & $-2,55$ & 1,77 & 1,34 & 0,74 & 1,34 & 0,74 & 1,34 & 1,30 & 1,13 & $-1,59$ \\
\hline $\begin{array}{l}\text { Simulação } 7 \text { - elimina somente } \\
\text { ineficiência no investimento da } \\
\text { administração pública }\end{array}$ & 0,09 & 2,30 & $-0,60$ & 2,30 & $-0,61$ & 2,31 & -0.61 & 2,31 & $-0,60$ & CT & 0,86 \\
\hline $\begin{array}{l}\text { Simulação } 8 \text { - elimina somente } \\
\text { ineficiência no investimento estatal }\end{array}$ & 0,30 & 0,12 & $-1,83$ & $-1,75$ & $-0,15$ & $-0,28$ & $-0,15$ & $-0,28$ & $-0,26$ & $-0,23$ & 0,32 \\
\hline $\begin{array}{l}\text { Simulação } 9 \text { - elimina somente } \\
\text { a ineficiência no consumo do } \\
\text { governo }\end{array}$ & $-0,37$ & $-1,08$ & $-1,44$ & $-1,07$ & $-0,60 \mid$ & $-1,07$ & $-0,60$ & $-1,07$ & $-1,04$ & $-0,91$ & 1,28 \\
\hline $\begin{array}{l}\text { Simulação } 10 \text { - elimina ineficiência } \\
\text { e corrupção nos investimentos da } \\
\text { administração pública. }\end{array}$ & $-0,13$ & 4,08 & $-0,75$ & 4,50 & 0,06 & 4,50 & 0,06 & 4,50 & 0,10 & 0,23 & 1,23 \\
\hline $\begin{array}{l}\text { Simulação } 11 \text { - elimina ineficiência } \\
\text { e corrupção nos investimentos das } \\
\text { estatais }\end{array}$ & 0,30 & 0,12 & $-3,19$ & $-3,09$ & $-0,15$ & $-0,27$ & $-0,15$ & $-0,27$ & $-0,26$ & $-0,23$ & 0,33 \\
\hline $\begin{array}{l}\text { Simulação } 12 \text { - elimina ineficiência } \\
\text { e corrupção no consumo da admi- } \\
\text { nistração pública }\end{array}$ & $-3,76$ & $-3,61$ & 0.32 & 0,24 & 0,13 & 0,24 & 0,13 & 0,24 & 0,23 & 0,20 & $-0,29$ \\
\hline $\begin{array}{l}\text { Simulação } 13 \text { - eliminação da ine- } \\
\text { ficiência com manutenção da cor- } \\
\text { rupção do consumo público }\end{array}$ & $-0,20$ & 3,09 & $-5,36$ & 0,17 & $-0,69 \mid$ & 3,09 & $-0,69$ & 3,09 & $-1,19$ & $-0,91$ & 2,85 \\
\hline
\end{tabular}

Fonte: Elaboração própria.

Legendas: $\mathrm{CP}=$ Curto Prazo; LP = Longo Prazo; $\mathrm{C}=$ Consumo; $\mathrm{I}=$ Investimento Privado; $\mathrm{Y}=$ Produto; $\mathrm{Cg}=$ Consumo do Governo; $\mathrm{H}=$ Horas Trabalhadas e $\mathrm{CT}=$ Constante.

${ }^{11}$ Denomina-se curto prazo (CP) o período imediatamente após as modificações nos parâmetros de corrupção e ineficiência e longo prazo (LP) o período em que economia já teria alcançado seu novo estado estacionário. 
Mantido tudo mais constante, eliminando-se a corrupção nos investimentos da administração pública (Simulação 4), um ganho de bem -estar correspondente a 0,43\% é obtido, indicando que a existência de corrupção desviando recursos de investimentos em infraestrutura, por exemplo, pode provocar efeito deletério sobre a eficiência e o bem-estar da economia.

Na Simulação 5, entretanto, a eliminação da corrupção nos investimentos estatais não provoca variações de bem-estar. Tudo mais constante, esta eliminação de corrupção ao reduzir desvios existentes nos investimentos das estatais e um efetivo aumento do estoque de capital destas empresas, induz reduções de curto e longo prazo nos investimentos privados (vide Quadro 6), provavelmente devido a um efeito crowding out, pois o capital das estatais aumenta enquanto o capital privado cai.

Vale destacar que, de acordo com o modelo, uma redução isolada da corrupção no consumo do governo (Simulação 6) gera efeito negativo e acentuado sobre o bem-estar, equivalente a $-1,59 \%$. A razão seria o elevado nível deste gasto e a hipótese de a sociedade atribuir um valor de utilidade para este de cerca de metade comparado ao consumo privado. Assim, a corrupção funciona como um fator positivo de realocação de recursos, sendo sua eliminação negativa do ponto de vista do bem-estar agregado da economia. Resultado, certamente, polêmico considerando os aspectos morais e distributivos da corrupção, mas que indicam o quanto os gastos de consumo do governo podem estar distorcendo a economia, de forma que a corrupção nestes gastos acabaria por determinar efeitos positivos em termos de eficiência alocativa para o conjunto da economia.

No sentido de realizar uma análise de sensibilidade do resultado desta última simulação no que tange ao bem-estar, foram realizadas duas simulações complementares nas quais se mostra como o bem-estar se comporta quando se altera o valor do parâmetro $\mu$, que reflete como o consumidor valoriza o consumo público per capita $\left(C g_{t}\right)$ com relação ao consumo privado $\left(C_{t}\right)$. Simulando com $\mu=1,0$, ou seja, famílias atribuindo igual valor para o consumo privado e os bens e serviços públicos utilizados, o bem-estar sai de $-1,59 \%$ para um bem-estar nulo. Na hipótese de $\mu=1,5$, o bem-estar passaria a ser positivo em $1,39 \%$. De acordo com o modelo, uma eliminação da corrupção no consumo do governo, mantido tudo mais constante, 
seria benéfica do ponto de vista do bem-estar agregado da economia, quando o consumidor atribui aos bens públicos valor superior ao consumo privado.

Quando se realiza a análise parcial mantendo-se a corrupção constante e eliminando, individualmente, os componentes de ineficiência, os resultados, como esperado, indicam que a eliminação da ineficiência sempre tem efeito positivo sobre o bem-estar e os efeitos sobre o produto e investimentos dependem do componente de ineficiência.

$\mathrm{Na}$ eliminação da ineficiência dos investimentos da administração pública, Simulação 7, ou, de acordo com o modelo, investimentos em infraestrutura, tem-se efeitos positivos, com aumentos significativos sobre os investimentos e produto em torno de 2,3\% no longo prazo. Resultados semelhantes aos da Simulação 4, que trata da eliminação da corrupção nos investimentos da administração pública, mantendose a ineficiência. No entanto, comparado ao da Simulação 4, o ganho de bem-estar da eliminação da ineficiência é superior $(x=0,84 \%)$, uma vez que os desvios de ineficiência correspondem a puro desperdício, enquanto os desvios de corrupção no modelo são internalizados como renda na economia. Quando se elimina a ineficiência dos investimentos das estatais, mantida a corrupção constante, Simulação 8, o produto, no longo prazo, reduz levemente em $0,2 \%$, o investimento se reduz razoavelmente, em torno de $1,1 \%$, e há uma elevação de bem-estar $(x=0,32 \%)$ em contraste com a Simulação 5, onde o bem - estar da economia não é afetado devido à eliminação da corrupção.

Os resultados constantes da Simulação 9, eliminação da ineficiência no consumo da administração pública com manutenção da corrupção, indicam expressivo ganho de bem-estar $(x=1,28 \%)$, em grande parte devido ao efetivo acesso ao consumo de bens públicos (aumento da fração 1-dc na função utilidade das famílias) e queda nos níveis de produto e investimento privado, ao contrário do crescimento nestas variáveis determinado por uma eliminação da corrupção com manutenção da ineficiência (Simulação 6), em que observa-se significativa perda de bem-estar. Outro conjunto de Simulações $(10,11$ e 12, do Quadro 6) é apresentado de forma a se verificar os efeitos da eliminação simultânea da corrupção e da ineficiência em cada um dos componentes de gastos, mantidos os valores dos outros componentes constantes. 
Na Simulação 10, admitindo-se uma simultânea eliminação da corrupção e da ineficiência no investimento da administração pública, o investimento e o produto aumentam significativamente no longo prazo, em torno de 4,5\%, e ocorre um expressivo ganho de bem-estar $(x=1,23 \%)$. Diferentemente, na Simulação 11, em que a eliminação ocorre no componente investimento estatal, tem-se queda do investimento $(-3,09 \%)$ e do produto $(-0,27 \%)$ no longo prazo, mas, embora menor, o ganho de bem-estar é positivo em 0,33\%. Quando a eliminação é no consumo público (Simulação 12), tem-se, no longo prazo, aumento leve do investimento privado e do produto, em torno de $0,24 \%$, e perda de bem-estar $(x=-0,29 \%)$, indicando que a perda de bem-estar determinada pela eliminação da corrupção neste componente $(\mathrm{x}=-1,59$, vide Simulação 6$)$ anula o efeito positivo sobre o bem-estar determinado pela eliminação da ineficiência $(x=1,28 \%$, vide Simulação 9). Verifica-se, assim, que, de acordo com o modelo, apesar do ganho de bem-estar de uma hipotética política de completa e simultânea eliminação da corrupção e ineficiência em todos os componentes dos gastos públicos ( $x=1,26 \%$, vide Simulação 1), a aplicação desta política apenas sobre um componente específico de gasto poderia gerar efeitos bastante diversos.

Por fim, na Simulação 13, eliminam-se todos os componentes de ineficiência e corrupção, exceto corrupção no consumo público, procurando neutralizar o efeito contrário que este impõe aos resultados obtidos anteriormente. Verifica-se, neste caso, aumentos significativos sobre o produto $(3,09 \%)$ e aumento leve nos investimentos privados $(0,17 \%)$, além do maior ganho de bem-estar nas simulações realizadas, cerca de 2,85\%. Ganho de bem-estar creditado às leves reduções do consumo privado $(-0,20 \%)$ e do consumo do governo no curto prazo (-0,69\%), acompanhadas de razoável redução nas horas trabalhadas $(-1,19 \%)$ e aos aumentos significativos nos níveis de consumo privado $(3,09 \%)$ e do governo $(3,09 \%)$ e redução, apesar de leve, nas horas trabalhadas no longo prazo $(-0,91 \%)$, além, obviamente, do aumento no efetivo acesso ao consumo de bens públicos (aumento da fração 1-dc na função utilidade das famílias) devido à eliminação do componente de ineficiência $(d c=d c r)$ no consumo do governo. 


\subsection{Substitutibilidade entre corrupção e ineficiência}

Nesta subseção verificam-se as consequências de um possível tradeoff existente entre corrupção e ineficiência, ambos componentes do desvio total, no sentido de quanto maior a quantidade de regras impostas ao setor público menor seria a corrupção, porém maior poderia tornar-se o componente de ineficiência nos investimentos das estatais e administração pública, bem como no consumo do governo. Na literatura de economia da corrupção há uma preocupação sobre um possível tradeoff existente entre corrupção e ineficiência. Teoricamente, Klitigaard (1994), Rose-Ackerman (2002), Tanzi (1998) e Myrdal (1972) sugerem o tradeoff quando preconizam que há uma relação direta entre poder discricionário dos agentes e a corrupção. Posição contrária encontra-se no trabalho empírico de Bandiera et al. (2007), que não encontraram correlação entre corrupção e ineficiência, no sentido de quanto mais regras menos corrupção e mais ineficiência econômica nos gastos públicos.

Com o propósito de investigar as consequências de eventuais políticas de redução da corrupção e ineficiência, admitindo-se haver tradeoff entre estes componentes de desvios, realizam-se 8 simulações, apresentadas no Quadro 7, para investigar efeitos macroeconômicos e de bem-estar destas políticas na hipótese de haver uma perfeita substitutibilidade entre corrupção e ineficiência.

A Simulação 14 apresenta uma política hipotética de eliminação da corrupção com custo de aumento da ineficiência na mesma proporção, ou seja, admitindo-se que estes componentes sejam substitutos perfeitos. Os resultados indicam aumentos significativos nos investimentos privados e no produto no curto e no longo prazo, acompanhados de forte aumento nas horas trabalhadas (ver Quadro 7). Entretanto, esta política implica redução no nível de bem-estar de $-3,85 \%$, devido à queda do consumo privado e o aumento das horas trabalhadas serem expressivas ao longo do tempo, além do efetivo acesso ao consumo de bens públicos, representado pela fração $1-d c$, não haver sofrido modificação, apesar da trajetória ascendente dos gastos de consumo do governo. Considerando-se a dimensão desta perda de bem-estar, um ambiente com um tradeoff dessa natureza, certamente, seria um relevante fator impeditivo para a adoção da política proposta. 
Invertendo as posições, Simulação 15, eliminando-se a ineficiência ao custo de um aumento na corrupção na mesma proporção, o produto e o investimento se reduzem significativamente, em quase 2,69\% no longo prazo, mas o bem-estar aumenta significativamente, algo em torno de 3,23\%, em decorrência do aumento do consumo e redução das horas trabalhadas, apesar da contínua redução do consumo público.

Simulando pelos componentes da corrupção e/ou da ineficiência, na forma das Simulações de 16 a 21 no Quadro 7, o padrão de perdas de bem-estar de eliminar a corrupção ao custo de aumento da ineficiência ocorre em todos os componentes de gastos do governo, tal como na Simulação 14, sendo, entretanto, mais pronunciada no componente consumo do governo que indica a maior perda de bem - estar $(x=-3,2 \%)$. Por outro lado, tal como na Simulação 15, uma política hipotética de eliminação da ineficiência ao custo de aumento na corrupção em igual proporção implica ganho de bem-estar em todos os componentes de gastos, sendo, novamente, particularmente relevante o ganho de bem-estar no componente consumo do governo $(\mathrm{x}=2,55 \%)$. 
Quadro 7 - Simulações supondo haver substitutibilidade entre corrupção e ineficiência

\begin{tabular}{|c|c|c|c|c|c|c|c|c|c|c|c|}
\hline \multirow{3}{*}{ SIMULAÇÕES } & \multicolumn{11}{|c|}{ Variações Percentuais em Variáveis Selecionadas } \\
\hline & \multicolumn{2}{|c|}{ C } & \multicolumn{2}{|c|}{ Ip } & \multicolumn{2}{|c|}{ Y } & \multicolumn{2}{|c|}{$\mathrm{Cg}$} & \multicolumn{2}{|c|}{ H } & \multirow{2}{*}{$\begin{array}{l}\text { Bem- } \\
\text { Estar }\end{array}$} \\
\hline & $\mathrm{CP}$ & LP & $\mathrm{CP}$ & LP & $\mathrm{CP}$ & LP & $\mathrm{CP}$ & LP & $\mathrm{CP}$ & LP & \\
\hline $\begin{array}{l}\text { Simulação } 14 \text { - elimina corrupção com } \\
\text { aumento de ineficiência na mesma } \\
\text { proporção. }\end{array}$ & $-3,53$ & $-1,46$ & 4,28 & 3,28 & 1,81 & 3,28 & 1,81 & 3.28 & 3,10 & 2,76 & $-3,85$ \\
\hline $\begin{array}{l}\text { Simulação } 15-\text { elimina ineficiência } \\
\text { com aumento da corrupção na mes- } \\
\text { ma proporção. }\end{array}$ & 2,91 & 1,18 & $-1,50$ & $-2,69$ & $-1,62$ & $-2,69$ & $-1,62$ & $-2,69$ & $-2,59$ & $|-2,27|$ & 3,23 \\
\hline $\begin{array}{l}\text { Simulação } 16 \text { - elimina corrupção e } \\
\text { aumenta ineficiência na mesma pro- } \\
\text { porção no investimento da administra- } \\
\text { ção pública. }\end{array}$ & $-0,30$ & $-0,12$ & 0,37 & 0,28 & 0,15 & 0,28 & 0,15 & 0,28 & 0,27 & 0,23 & $-0,33$ \\
\hline $\begin{array}{l}\text { Simulação } 17 \text { - elimina corrupção } \\
\text { e aumenta ineficiência na mesma } \\
\text { proporção nos investimentos das } \\
\text { estatais. }\end{array}$ & $-0,27$ & $-0,11$ & 0,32 & 0,25 & 0,14 & 0,25 & 0,14 & 0,25 & 0,24 & 0,21 & $-0,29$ \\
\hline $\begin{array}{l}\text { Simulação } 18 \text { - elimina corrupção e } \\
\text { aumenta ineficiência na mesma pro- } \\
\text { porção no consumo do governo. }\end{array}$ & $-2,94$ & $-1,22$ & 3,57 & 2,74 & 1,51 & 2,73 & 1,51 & 2,73 & 2,63 & 2,30 & -3.20 \\
\hline $\begin{array}{l}\text { Simulação } 19 \text { - elimina ineficiência e } \\
\text { aumenta corrupção na mesma propor- } \\
\text { ção no investimento da administração } \\
\text { pública }\end{array}$ & 0,33 & 0,13 & $-0,40$ & $-0,30$ & $-0,17$ & $-0,30$ & $-0,17$ & $-0,30$ & $-0,29$ & $|-0,26|$ & 0,36 \\
\hline $\begin{array}{l}\text { Simulação } 20 \text { - elimina ineficiência e } \\
\text { aumenta corrupção na mesma propor- } \\
\text { ção nos investimentos das estatais. }\end{array}$ & 0,30 & 0,12 & $-0,36$ & $-0,27$ & $-0,15 \mid$ & $-0,28 \mid$ & $-0,15$ & $-0,28 \mid$ & $-0,26$ & $-0,23$ & 0,32 \\
\hline $\begin{array}{l}\text { Simulação } 21 \text { - elimina ineficiência e } \\
\text { aumenta corrupção na mesma propor- } \\
\text { ção no consumo do governo. }\end{array}$ & 2,35 & 0,94 & $-2,84$ & $-2,14$ & $-1,19$ & $-2,13$ & $-1,19$ & $-2,13$ & $-2,05$ & $-1,80$ & 2,55 \\
\hline
\end{tabular}

Fonte: Elaboração própria.

Legendas: $\mathrm{CP}=$ Curto Prazo; $\mathrm{LP}=$ Longo Prazo; $\mathrm{C}=$ Consumo; $\mathrm{I}=$ Investimento Privado; $\mathrm{Y}=$ Produto; $\mathrm{Cg}=$ Consumo do Governo; $\mathrm{H}=$ Horas Trabalhadas.

Todas as simulações do Quadro 7 tratam de mostrar os resultados gerados pelo modelo para os casos de substitutibilidade perfeita entre corrupção e ineficiência, designando, portanto, situações de escolha entre opções conflitantes, ou seja, a existência de tradeoff. Como uma possibilidade de ilustração desse tradeoff, referencia-se o caso da Lei Federal no 12462/2011, que trata do Regime Diferenciado de Contratação Pública - RDC para as obras e os serviços de engenharia relativas à Copa do Mundo de Futebol de 2014 e aos Jogos 
Olímpicos de 2016, que criou, temporariamente, procedimentos licitatórios mais flexíveis e aumentou o poder discricionário dos agentes públicos, quando comparados a Lei de Licitação no 8.666/93.

De acordo com o Governo Federal, as medidas de flexibilização dos procedimentos licitatórios seriam necessárias para aumentar a eficiência das contratações tanto em termos de tempo como de qualidade. No entanto, para o Ministério Público Federal, que entrou com uma Ação Direta de Inconstitucionalidade - ADIN no Supremo Tribunal Federal, alguns pontos da RDC, principalmente quanto à opção preferencial na contratação integrada (uma única licitação para projeto básico, projeto executivo e execução de obras e serviços), a adoção das medidas de flexibilização aumenta o risco de desvios e encarece as obras. O MPF entende que a RDC gera concentração dos instrumentos em uma única empresa (ou consórcio) aumenta o poder da contratada, permite a ocorrência de alterações sem a devida necessidade e transparência, torna mais complexa a fiscalização, devido a não fixar parâmetros mínimos para identificar obras, serviços e compras que devam seguir. Além disso, o MPF alega que a experiência mostra o risco que essa delegação representa ao patrimônio público, visto que, por ocasião dos Jogos Panamericanos, os órgãos públicos não conseguiram organizar-se e identificar as obras e os serviços necessários, o que gerou uma extrapolação das estimativas do evento de $\mathrm{R} \$ 300$ milhões para $\mathrm{R} \$ 3$ bilhões. (Fonte: ADIN $\mathrm{n}^{\circ}$ 4655/2011, www.stf.jus.br, pesquisado em 06/02/2012).

Quando se considera a existência de tradeoff entre corrupção e ineficiência, como na Simulação 15, onde se eliminam as ineficiências ao custo de aumentos na corrupção, ocorrem reduções no produto e no investimento privado e ganho de bem-estar expressivo de 3,23\%. Assim, em vista dos resultados gerados pelo modelo, pode-se especular que a flexibilização permitida pela Lei no 12.462/2011, no caso de implicar aumento de corrupção, o que teoricamente é possível já que o excesso de poder discricionário é uma das causas da corrupção (ver Klitigaard, 1994; Rose-Ackerman, 2002), poderia determinar ganho de bem-estar para o agregado da economia, mas retrairia as trajetórias de crescimento do produto e investimento no curto e longo prazo. 


\section{Conclusões}

Os resultados dos exercícios contrafactuais realizados mostram que quando há eliminação da corrupção, em geral, aumenta-se o investimento privado e o produto no longo prazo. Portanto, os resultados de longo prazo gerados nas simulações estão alinhados aos obtidos na literatura de economia da corrupção, principalmente com os de Mauro (1995), Tanzi (1998), Treisman (2000), Lambsdorff (2003) e Kaufmann et al. (2002), Pelegrini e Gerlagh (2004), MartinezVasquez et al. (2005).

Supondo a eliminação da ineficiência e corrupção nos gastos públicos, os resultados indicam que, no longo prazo, têm-se efeitos positivos consideráveis, os investimentos privados se elevam, bem como as horas trabalhadas, impactado pela melhoria da eficiência, o produto aumenta significativamente, sendo sua trajetória, no novo estado estacionário, quase $4,5 \%$ superior à trajetória determinada por seu estado estacionário inicial, e o bem-estar neste cenário implicaria ganhos de eficiência equivalentes a um aumento permanente de $1,26 \%$ nos níveis de consumo anteriores ao choque. Resultado significativo, comparável a choques como uma reforma tributária no Brasil (Araújo e Ferreira (1999)) e aos efeitos potenciais da política de Parceria Público-Privada no Brasil (Pereira e Ferreira (2008)).

$\mathrm{Na}$ simulação onde se mantêm as ineficiências, mas todos os tipos de corrupção supostos no modelo são eliminados, o resultado encontrado é uma queda no nível de bem-estar equivalente a $-1,17 \%$, indicando que a corrupção estaria corrigindo alguma distorção presente na economia. Entretanto, ao se manter os demais tipos constantes e eliminando corrupção somente nos investimentos da administração pública, tem-se ganho de bem-estar de $0,43 \%$ e efeitos positivos expressivos no crescimento do produto e investimento no longo prazo, indicando que a existência de corrupção e desvio de recursos de investimentos em infraestrutura, por exemplo, pode provocar efeito deletério sobre o crescimento e o bem-estar da economia. Resultado de extrema importância, principalmente quando se considera que os investimentos em infraestrutura são complementares aos investimentos privados, que o papel do governo na oferta destes serviços é bastante relevante e que existe uma reconhecida carência de infraestrutura no Brasil, amplamente debatida pela mídia e alardeada em inúmeros trabalhos acadêmicos. 
Por outro lado, de acordo com o modelo, uma redução isolada da corrupção no consumo do governo gera efeito negativo e acentuado sobre o bem-estar, cerca de $-1,6 \%$, provavelmente, devido ao elevado nível deste gasto e a sociedade atribuir um valor de utilidade para este de cerca de metade comparado ao consumo privado e a corrupção funcionar, assim, como um fator positivo de realocação de recursos. Resultado, certamente, polêmico, considerando os aspectos morais e distributivos da corrupção, mas que indicam o quanto os gastos de consumo do governo podem estar distorcendo a economia, de forma que a corrupção nestes gastos acabaria por determinar efeitos positivos em termos de eficiência alocativa para o conjunto da economia. Cabe frisar que há a possibilidade de o consumo do governo ser alto em vista da existência da corrupção, o que requer orçar um nível de gasto maior que o necessário, assim, como futura pesquisa, poder-se-ia verificar como se comportaria o nível de gasto no caso de uma redução de corrupção e os efeitos desse processo endógeno sobre o bem-estar.

Quanto aos impactos ao se considerar a existência de um possível tradeoff entre políticas de redução de ineficiências ao custo de aumentos na corrupção, os resultados encontrados nas simulações indicam efeitos negativos sobre o produto e o investimento no curto e longo prazos, em que pese o bem-estar aumentar. Verificou-se, inversamente, que há uma redução do bem-estar do agregado da economia quando corrupção cai e a ineficiência aumenta.

Usando como ilustração a implementação do Regime Diferenciado de Contratação, que consiste de uma flexibilização das normas licitatórias para as obras da copa do mundo e das olimpíadas, os resultados das simulações sugerem que se a flexibilização permitida pela Lei $\mathrm{n}^{\circ} 12.462$ vier acompanhada de aumentos na corrupção, o que teoricamente é possível já que o excesso de poder discricionário é uma das causas da corrupção (ver Klitigaard, 1994; Rose-Ackerman, 2002), poderia haver ganho de bem-estar para o agregado da economia, mas retrairia as trajetórias de crescimento do produto e investimento no curto e longo prazo, mostrando que poderia haver certo dilema na tomada de decisão para fins de implantação de uma política desta natureza. 


\section{Referências}

ACEMOGLU, D.; VERDIER, T. The choice between market failures and corruption. American Economic Review, v. 90, p. 194-211, 2000.

ARAÚJO, C. H. V.; FERREIRA, P. C. Reformas Tributárias no Brasil: Efeitos Alocativos e Impactos de Bem-Estar. Revista Brasileira de Economia, v. 53, n. 2, p.133-166, 1999.

ASCHAUER, D. A. Fiscal Policy and Aggregate Demand. American Economic Review, v. 75, n. 1, p. 117-127, 1985.

Is public expenditure productive. Journal of Monetary Economic, v. 23, 1989.

BANDIERA, Oriana; PRAT, Andrea; VALLETI, Tommaso.Active and Passive Waste in Government Spending: Evidence from a Policy Experiment. American Economic Review, 99(4): p.1278-1308, 2009.

BARRO, Robert. Output effects of governments purchases. Journal of Political Economy, dec. 1981.

BARRO, R. J. Government spending in a simple model of endogenous growth. The Journal of Political Economy, v. 98, n. 5, p. 103-125, 1990.

BARRO, R. Economic growth in a cross-section of countries. Quarterly Journal of Economics, v. 106, p. 407-443, 1991.

BARRO, R. J.; SALA-I-MARTIN, X. Economic Growth.MIT Press, 2004.

BEATTIE, Alan. Falsa Economia. Rio de Janeiro: Editora Zahar, 2010.

BECKER, Gary S. Crime and Punishment: An Economic Approach. Journal of Political Economy, v. 76, n. 2, p. 169-217, 1968.

BLACKBURN, K.; BOSE, N.; HAQUE, M.E. The incidence and persistence of corruption in economic development. Journal of Economic Dynamics and Control, v. 30, p. 2447-67, 2006.

CARRARO, A.; FOCHEZATTO, A.; HILLBRECHT, R. O Impacto da Corrupção sobre o Crescimento Econômico do Brasil: aplicação de um Modelo de Equilíbrio Geral para o período 1994-1998. In: XXXIV Encontro Nacional de Economia, 2006, Salvador. Anais do XXXIV Encontro Nacional de Economia, 2006. http://www.anpec.org.br/encontro2006/artigos/A06A057.pdf . Acessado em 21/10/2009.

CHAKBARTI, Rajesh. Corruption: A general equilibrium approach. Working Paper. Disponível em: $<$ http//www.prism.gatech.edu/ rc166/corruption.pdf $>$ Acesso em 21/06/2011.

CHEUNG, S. A Simplistic General Equilibrium Theory of Corruption. Contemporary Economic Policy, V. 14 , n. 3, p. 1-7, 1996.

CHRISTIANO J. Lawrence; EICHEMBAUM, Martin. Current real business cycle theories and aggregate labor-market fluctuations. American Economic Review, 1992.

COOLEY, T; HANSEN, Gary D. The Welfare Costs of Moderate Inflations. Journal of Money, Credit and Banking, Vol. 23, No. 3, Part 2: Price Stability. 1991, pp.483-503.

COOLEY, T. F; PRESCOTT, E. Economic Growth and Business Cycles, em Cooley, T. (ed.) Frontiers of Business Cycles Research, Princeton Press, 1995.

DABRA-NORRIS, Era; BRUMBY, Jim; KYOBE, A.; MILLS, Zac Mills; PAPAGEORGIOU, Chris. Investing in Public Investment: An Index of Public Investment Efficiency.IMF Working Paper, WP/11/37, 2011. Disponível em: <www.imf.org/external/pubs/ft/wp/2011/wp1137.pdf> Acesso em 18/12/2011.

DI TELLA, Rafael; SCHARGRODSKY, Ernesto. The Role of Wages and Auditing during a Crackdown on Corruption in the City of Buenos Aires. Journal of Law and Economics, v. 46, n. 1, 2004.

DZHUMASHEV, Ratbek. Is there a direct effect of corruption on growth? MPRA Working paper, $\mathrm{n}$. 18489, 2009. 
EASTERLY, Willian. O Espetáculo do Crescimento. Rio de Janeiro: Ediouro, 2004.

EASTERLY, William; LEVINE, Ross. Tropics, Germs, and Crops: How Endowments Influence Economic Development. NBER Working Paper Series, n. 9106, 2002.

ELLIOT, Kimberly Ann (Org). A Corrupção e a Economia Global. Brasília: Editora UNB, 2002.

FERRAZ, Claudio; FINAN, Frederico. Electoral Accountability and Corruption in Local Governments: Evidence from Audit Reports. Working paper, UCLA, 2007.

FERREIRA, P.C; ARAÚJO, C. V. On the economic and fiscal effects of infrastructure investment in Brazil. Ensaios Econômicos, EPGE/FGV, Rio de Janeiro, n. 613, 2006.

FERREIRA, P. C.; ISSLER, J. V. Time series properties and empirical evidence of growth and infrastructure. Revista de Econometria, v. 18, n. 31, 1998.

FERREIRA, P.C; MALLIAGROS, Thomas G. Investimentos, fontes de financiamento e evolução do setor de infraestrutura no Brasil: 1950-1996. Ensaios Econômicos nº 346, RJ:FGV-EPGE, 1999.

FERREIRA, P. C.; NASCIMENTO, L. G. Welfare and growth effects of alternative fiscal rules for infrastructure investment in Brazil. Ensaios Econômicos EPGE 604. Fundação Getúlio Vargas, 2005.

FIDIC (International Federation of Consulting Engineers). Canadian Consulting Engineer http:// www.canadianconsultingengineer.com/companies-people/corruption-means-10-loss-in-worldinfrastructure-investment/1000810396/. January 9, 2012. Acesso em 25/03/2012.

FIESP - Índice de Percepção da Corrupção - 2010. Questões para Discussões. DECOMTEC - Área de Competitividade. Agosto de 2011. Disponível em: <http://www.fiesp.com.br/competitividade/ downloads/indice $\% 20 \mathrm{de} \% 20$ percep $\% \mathrm{C} 3 \% \mathrm{~A} 7 \% \mathrm{C} 3 \% \mathrm{~A} 3 \mathrm{o} \% 20 \mathrm{da} \% 20$ corrup $\% \mathrm{C} 3 \% \mathrm{~A} 7 \% \mathrm{C} 3 \%$ A30\%20-\%202011.pdf>). Acesso em 21/03/2012.

FISMAN, Raymond; GATTI, Roberta. Decentralization and Corruption: Evidence across Countries. Journal of Public Economics, v. 83, n. 2, p. 325-45, 2002.

GLOMM, G; RAVIKUMAR, B. Public Investment in Infrastructure in a Simple Growth Model. Journal of Economic Dynamics and Control, v. 18, p. 1173-1187, 1994.

GLOMM, G; RAVIKUMAR, B. Productive Government Expenditures and Long-Run Growth. Journal of Economic Dynamics and Control, v. 21, p. 183-204, 1997.

GOMES, Victor; ELLERY JR, Roberto; BUGARIN, Mirta N.S. Long Run Implication of the Brazilian Capital Stock and Income Estimate. Proceding of the 2002 Latin American Meeting of the Econometric Society, 2002.

GUPTA, Sanjeev; KANGUR, Alvar; PAPGEORGIOU Chris; WANE, Abdoul.Efficiency-Adjusted Public Capital and Growth.IMF Working Paper WP 11/27, 2011. Disponível em: <www.imf.org/ external /pubs/ft/wp/2011/wp11217.pdf> Acesso em 18/12/2011.

HOBBS, N. Corruption in World Bank Projects: why bribery is a tolerated anathema. Working Paper 05-61, 2005. Disponível em:<www2.ISE.al.uk/internationaldevelopment/pdf/wp65.pdf> Acesso em 21/12/2011.

KANCZUK, Fábio. Juros reais e ciclos reais de negócios brasileiros. Revista Brasileira de Economia, Rio de Janeiro, v. 56, n. 2, p. 249-267, Abr/Jun 2002.

KAUFMANN, D; KRAAY, A.; MASTRUZZI, M. Governance Matters III: Governance Indicators for 1996-2002 (Policy Research Working Paper Series 3106). Washington, DC: World Bank, 2002.

KLITIGAARD, Robert. A Corrupção Sob Controle. Rio de Janeiro: Jorge Zahar Editor, 1994.

LAMBSDORFF, Johann Graf. How Corruption Affects Productivity. Kyklos, v. 56, n. 4, 2003.

LEVINE, R; RENELT, D., 'A sensitivity analysis of cross-country growth regressions',

American Economic Review 82(4), pp. 942-963, 1992.

LLEDO, Victor Duarte. Tax Systems under Fiscal Adjustment: A Dynamic CGE Analysis of the Brazilian Tax Reform. IMF Working Paper, WP/05/142. 2005.

LUCAS, R. Models of Business Cycles. Cambridge, MA: Basil Blackewell, 1987.

Estud. Econ., São Paulo, vol.46, n.2, p. 373-408, abr.-jun. 2016 
MANKIW, N. G; ROMER, D.; WEIL, D. N. A contribution to the empirics of economic growth. Quarterly Journal of Economics, v. 107, n. 3, p. 407-437, 1992.

MARTINEZ-VAZQUEZ, Jorge; MCNAB, Robert M.; EVERHART, Stephen S. Corruption, Investment, and Growth in Developing Countries. Working Paper Series 04, 2005.Diponível em: $<$ http://www.nps.edu/Academics/Centers/DRMI/docs/ drmi\%20working\%20paper\%2005-04. pdf> Acesso em 27/06/2011.

MAURO, P. Corruption and Growth. Quarterly Journal of Economics, v. 110, n. 3, p. 681-712, 1995. . Corruption and the Composition of Government Expenditure. Journal of Public Economics, v. 69 , n. 2, p. 263-279, 1998.

Os efeitos da corrupção sobre o crescimento, investimento e gastos do governo: uma análise de países representativos. In: ELLIOT, Kimberly Ann (org). Corrupção e a Economia Global. Brasília: Editora UNB, 2002.

MUNNELL, Alicia H. Infrastructure Investment and Economic Gorwth. The Journal of Economic Perspective, v.6, n.4, pg 189-198, 1992

MUSSOLINI, Caio Cesar. Ensaios em Política Fiscal. Tese de Doutorado da FGV-SP, São Paulo, 2011.

MYRDAL, Gunnar. Asian Drama: An Inquiry into the Poverty of Nations. New York: Vintage Books, 1972.

NEEMAN, Z.; PASERMAN, D.; SIMHON, A. Corruption and Openness, C.E.P.R. Discussion Papers, n. 4057, 2003.

OLKEN, Benjamin A. Corruption Perceptions vs. Corruption Reality.National Bureau of Economic Research, n.12428, 2006. <http://www.nber.org/papers/w10460> . Acesso em 27/07/2011.

PELLEGRINI, L.; GERLAGH, R. Corruption's Effect on Growth and Its Transmission Channels. Kyklos, v. 57, n. 3, p. 429-456, 2004.

PEREIRA, Ricardo A de Castro; FERREIRA, Pedro C. Efeitos de Crescimento e Bem-estar da Lei de Parceria Público-Privada no Brasil. Revista Brasileira de Economia, v. 62, n. 2, p. 207-219, Abr-Jun, 2008.

Avaliação dos Impactos Macro-Econômicos e de Bem-Estar da Reforma Tributária no Brasil. Revista Brasileira de Economia, v. 64, p. 191-208, 2010.

Impactos Macroeconômicos da Cobrança pelo Uso da Infraestrutura Pública no Brasil. Pesquisa e Planejamento Econômico, v. 41, n. 2, p. 183-212, 2011.

PRITCHETT, Lant. The tyranny of concepts: CUDIE (cumulated, depreciated,inve stment edort) is not capital. Journal of Economic Growth, v. 5, n. 4, p. 361-384, 2000.

ROSE-ACKERMAN, Susan.. A Economia Política da Corrupção. In: ELLIOT, Kmberly Ann (Org), Corrupção e a Economia Global. Brasília: Editora UNB, 2002.

SHLEIFER, Andrei; VISHNY, Robert W. Corruption. Quarterly Journal of Economics, v. 108, p. 599-617, 1993.

SILVA, Marcos Fernandes Gonçalves; GARCIA, Fernando; BANDEIRA, Andréa Câmara. How does Corruption hurt growth? Evidence about the effects of corruption on factors productivity and per capita income. Disponível em: < http://core.ac.uk/download/pdf/6239429.pdf>. Acesso 24/05/2015.

SVENSSON, J. Eight Questions About Corruption. Journal of Economic Perspective, v. 19, n. 3, p. 19-42, 2005.

TANZI, Vito. Corruption Around The World. IMF Staff Papers, v. 45, dec/1998.

TANZI, Vito; DAVOODI, Hamid. Corruption, Public Investment, and Growth, International Monetary Fund Working Paper, n. 97/139, 1997.

TRANSPARÊNCIA INTERNACIONAL. Índice de Corrupção Percebida. Disponível em: http://www. transparency.de/index.html. 
TREISMAN, Daniel. The Causes of Corruption: A Cross-National Study, Journal of Public Economics, 76: 399-457, 2000.

TRIBUNAL DE CONTAS DA UNIÃO (TCU). Relatórios de Fiscalizações de Obras (FISCOBRAS). Disponível em: <www.tcu.gov.br>. Acesso em: 25 ago. 2011.

TULLOCK, Gordon. The Welfare Costs of Tarrifs, Monopolies and Theft. Western Economic Journal, v. 5, p. 224-232, 1967.

TURNOVSKY, S. J.; FISHER, W. H. The Composition Of Government Expenditure And Its Consequences For Macroeconomic Performance, Journal of Economic Dynamics and Control, v. 19, n. 4, p. 747-786,1995.

UGUR, Mehmet; DASGUPTA, Nandini. Corruption and economic growth: A meta-analysis of the evidence on low-income countries and beyond. MPRA Paper, n. 31226, June 2011. Disponível em: http://mpra.ub.uni-muenchen.de/31226. Acesso em 21/02/2012.

WEDEMAN, Andrew. Looters, Rent-Scrapers, and Dividend-Collectors: Corruption and Growth in Zaire, South Korea, and the Philippines. The Journal of Developing Areas, v. 31, n. 4, p. 457-478, 1997. Disponível em: <http://www.jstor.org/stable/4192713>. Acessado 21/ 02/2012.

WORLD BANK. World Development Report 1997. Washington D.C.: World Bank, 1997. 